\title{
Prevalence of Bacterial Urinary Tract Infections and Their Anti-microbial Susceptibility Test in a Tertiary Care Hospital in Bangladesh between April 2020 to April 2021
}

\author{
Aklima Akter ${ }^{1}$, \\ Associate Professor Dr Md Arifur Rahman ${ }^{2}$, Assistant Professor Dr Farhana Khan ${ }^{3}$, \\ Associate Professor Dr Asma Akter Abbasy ${ }^{4}$, Assistant professor Dr Farjana Sultana ${ }^{5}$ \\ *Corresponding author: \\ Aklima Akter ${ }^{1}$ (corresponding author) \\ MSc in Microbiology (Scientific officer) \\ Department of Microbiology Brahmanbaria Medical College, Brahmanbaria, Bangladesh \\ Mobile No: +880 1732647980 email: aklimabmc@gmail.com
}

doi: 10.51505/ijmshr.2021.5609

URL: http://dx.doi.org/10.51505/ijmshr.2021.5609

\begin{abstract}
Urinary tract infection is the most common bacterial infection in Bangladesh and a common disease of women than men. An antimicrobial agent is used for the treatment of UTI. The increase in antibiotic resistance among uropathogens is a global problem. This study attempted to underline the prevalence of UTI patients affected by uropathogenic strains. The study was conducted among 3060 patients of different ages and sex from over a period of one year April 2020 to April 2021 through conventional cultural, biochemical methods as well as disk diffusion methods to determine the uropathogens and their antibiotic susceptibility pattern. Among 3060 samples, $1148(37.5 \%)$ samples were found culture positive, $248(22 \%)$ cases positive for male \& 900 (78\%) cases positive for females. Most of the UTI was caused by Escherichia coli 891 (60 $\%)$. Moreover Enterobacter spp (7.5\%), Pseudomonas aeruginosa (11\%), Proteus vulgaris (3.5\%), Proteus mirabilis (2.5\%) Citrobacter freundii (1\%), Klebsiella pneumoniae (3\%), Staphylococcus spp (9.5\%) Enterococcus faecalis (2\%). 17 antibiotics were used against the isolated uropathogens. As it can be seen from (Table 2) Escherichia coli are sensitive to Meropenem 89\%, Amikacin 80\%, Gentamicin 74\%, Nitrofuration 67\%, Amoxiclave 71\%, Ciprofloxacin 41\%, Levofloxacin 37\%, Doxycycline 40\%. Pseudomonas aeruginosa sensitive to to Meropenem 72\%, Amikacin 79\%, Gentamicin 72\%, Nitrofuration 54\%, Amoxiclave 60\%, Ciprofloxacine 43\%, Levofloxacine 47\%. Klebsiella Pneumoniae to Meropenem 82\%, Amikacin $71 \%$, Gentamicin 71\%, Nitrofuration 50\%, Amoxiclave 63\%, Ciprofloxacin 32\%, Levofloxacine 38\%. Staphylococcus Spp Meropenem 83\%, Amikacin 79\%, Gentamicin 73\%, Nitrofuration
\end{abstract}




\section{International Journal of Medical Science and Health Research}

Vol. 5, No. 06; 2021

ISSN: $2581-3366$

60\%, Amoxiclave 70\%, Ciprofloxacine 46\%, Levofloxacine 43\%, Lenazolid 30\%, Cotrimoxazole 43\%. Proteus vulgaris Meropenem 84\%, Amikacin 86\%, Gentamicin 82\%, Nitrofuration 56\%, Amoxiclave 35\%, Ciprofloxacine 28\%, Levofloxacine 40\%, Doxycycline $30 \%$. Proteus mirabilis Meropenem 86\%, Amikacin 84\%, Gentamicin 84\%, Nitrofuration 60\%, Amoxiclave 63\%, Ciprofloxacine 31\%, Levofloxacine 43\%, Doxycycline 30\%. Enterobacter Spp Meropenem 78\%, Amikacin 68\%, Gentamicin 70\%, Nitrofuration 47\%, Amoxiclave 58\%, Ciprofloxacin 38\%, Levofloxacine 41\%, Doxycycline 37\%. Enterococcus faecalis Meropenem $80 \%$, Amikacin 80\%, Gentamicin 73\%, Nitrofuration 59\%, Amoxiclave 68\%, Ciprofloxacine $30 \%$, Levofloxacine 20\%, Lenazolid 32\%, Cotrimoxazole 43\%. Citrobacter freundii Meropenem $88 \%$, Amikacin 83\%, Gentamicin 82\%, Nitrofuration 60\%, Amoxiclave 61\%, Ciprofloxacin $33 \%$, Levofloxacine $32 \%$, Ceftriaxone $30 \%$, Doxycycline $30 \%$.

Keywords: Urinary Tract Infection (UTI), Uropathogens, Anti-microbial susceptibility test, Antibiotics, E.coli.

\section{Introduction:}

A urinary tract infection is an infection that affects any parts of the Urinary tract 29 . When it affects the lower urinary tract it is known as a bladder infection (cystitis) and when it affects the upper urinary tract it is known as a kidney infection 30. Symptoms from a lower urinary tract infection include pain with urination, frequent urination, and feeling the need to urinate despite having an empty bladder 29. Symptoms of an upper urinary tract infection include fever and pain usually in addition to the symptoms of a lower UTI 30.

Urinary Tract Infection is the most common bacterial infection occurring in women than men through males over the 60 years with prostatic hypertrophy are the exceptions 1. Many researchers reported that $60 \%$ of women suffer from this infection at any phase of their lifetime and 20-30\% of people suffer from repeated infection 2. UTI are infections caused by the presence and growth of microorganisms anywhere in the urinary tract and is perhaps the single commonest bacterial infection of human 3. The urinary tract consists of the kidney, ureter, bladder, and urethra and any part of these structures can become infected and UTI is the infection of any part of this tract. Where bacteria can enter into the sterile urinary system through the urethra or more rarely through the bloodstream 4 . Women are more susceptible to UTI than men because the urethra is much shorter and closer to the anus in females 5. Major risk factors behind this common UTI are an unhygienic lifestyle, using contaminated water to clean after urination, sexual activation like sex with multiple partners without condoms 5, 6

Escherichia coli is the most common Uropathogen of all forms of UTI and is responsible for $80 \%$ of Cases 7,8. Though Escherichia coli is the most common causative agent of UTI but, Pseudomonas spp, Enterobacter spp, Gram-positive Enterococcus faecalis, Proteus spp, Klebsiella, and Staphylococcus saprophyticus are also responsible for UTI 2,9.

UTI was verified by burning or pain, dark urine, strong smell, and urination urgency 10. UTIs can occur as asymptomatic bacteriuria, acute cystitis, and acute pyelonephritis 11. Fever and 


\section{International Journal of Medical Science and Health Research}

Vol. 5, No. 06; 2021

ISSN: $2581-3366$

chills are common along with other systemic symptoms and board spectrum therapy is required 12.

The aim of a microbiology laboratory is to diagnose UTI accurately and timely. Aim also includes appropriate antimicrobial sensitivity testing 13. The development of resistant strains is a common problem in antimicrobial chemotherapy. The frequency of resistance to antibiotics and is directly linked to the consumption of antibiotics 14. Due to improper use of antibiotics the prevalence of antimicrobial resistance among urinary pathogens has been increasing worldwide $15,16$.

Consequently, the aim of this research was to identify the uropathogenes isolated from the local patient of district of Brahmanbaria in Bangladesh as well as evaluate the antimicrobial susceptibility patterns of the causative UTI agent in recent time.

\section{Methodology}

This study was carried in the Department of Microbiology of Brahmanbaria Medical College over a period of one year from April 2020 to April 2021. This is a very well recognized and governmentally approved 400 beds hospital in the District of Brahmanbaria under the city of Chittagong in Bangladesh where all the patients were registered by their personal information according to the rules of the organization. Midstream urine samples (MSU) were collected in sterile wide-mouthed screw-capped containers from the 3060 patients including males \& females. Culture the urine sample was inoculated on 5\% sheep blood agar and MacConkey's agar media using calibrated loop following standard bacteriological technique and incubated at $37^{\circ} \mathrm{c}$ for 24 hours. After the incubation period, the plates were examined for the bacterial pathogen. Pure bacterial colony counting $\geq 10^{5}$ bacteria/ml were considered as significant and was subjected to identification based on colony characters and biochemical test, Gram staining 17,18. Isolated colonies from MacConkey's agar media \& blood agar media were processed for Gram staining by following the steps (primary stain-crystal violet, mordanting - grams iodine, decolorizer- acetone, counterstain- safranin. After the staining colonies of different isolated microorganisms were observed under the microscope and identified 19. Finally, the standard biochemical test which includes catalase, coagulase, indole, urease, oxidase, citrate, and test were performed aimed to identify the bacterial isolate (Table-2).

\section{Antimicrobial susceptibility testing:-}

All the isolates were tested for antibiotic susceptibility against 17 antimicrobial drugs (including first, second \& third generation drugs) by disc diffusion assay on Mueller- Hinton agar with antibiotic discs according to the modified Kirby-Bauer method. A single colony of each isolate was inoculated into $2 \mathrm{ml}$ Mueller-Hinton broth and incubated at $37^{\circ} \mathrm{c}$ for 24 hours. The culture turbidity was adjusted to $0.5 \mathrm{McFarland}$ standard. Sterile cotton swabs were dipped into the suspensions and spread evenly over the entire surface of Muller-Hinton agar. Antibiotic discs of appropriate concentration were placed aseptically over the surface at an appropriate spatial distance of $5 \mathrm{~mm}$. Plates were then inverted \& incubated at $37^{\circ} \mathrm{c}$ After 24 hours plates were examined and the diameters of the zones of inhibition were measured and interpreted as susceptible intermediate and resistant 20,21. 


\section{Result:}

According to this research Table -1, 1148 (37.5\%) positive cases of UTI were found from a total of 3060 urine samples where the Male participant was 972 (32\%) \& the Female participant was 2088 (68\%). Out of 1148 UTI-positive patients, 248 cases were positive for males which is $22 \%$ \& 900 positive cases were positive for females which $78 \%$ (Figure -1 ).

Table 1 Sex distribution among susceptible population (n-3060).

\begin{tabular}{|c|c|c|c|}
\hline \multirow{2}{*}{ Gender } & Total & \multicolumn{2}{|c|}{ Growth } \\
\cline { 3 - 4 } & & Positive & Negative \\
\hline Male & $972(32 \%)$ & $248(22 \%)$ & $724(38)$ \\
\hline Female & $2088(68 \%)$ & $900(78 \%)$ & $1188(62)$ \\
\hline Total & $3060(100 \%)$ & $1148(37.5)$ & $1912(62.5)$ \\
\hline
\end{tabular}

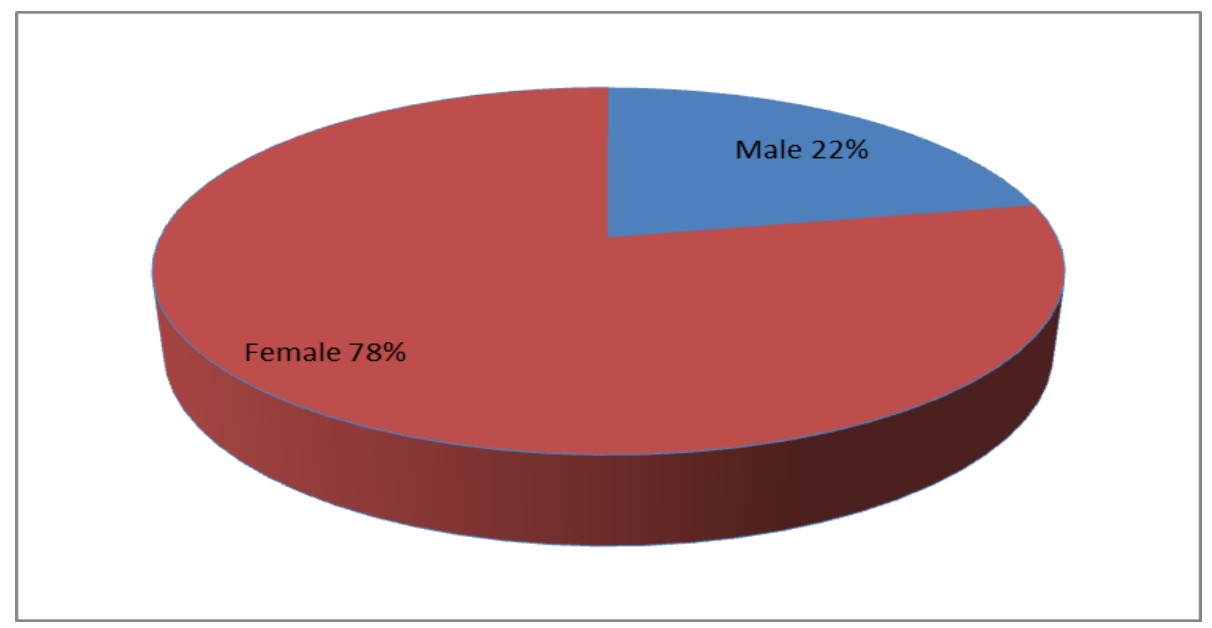

Figure 1: Pie chart showing sex distribution of isolated UTI patients. Out of 1148 positive females were $900(78 \%)$ and males were $248(22 \%)$.

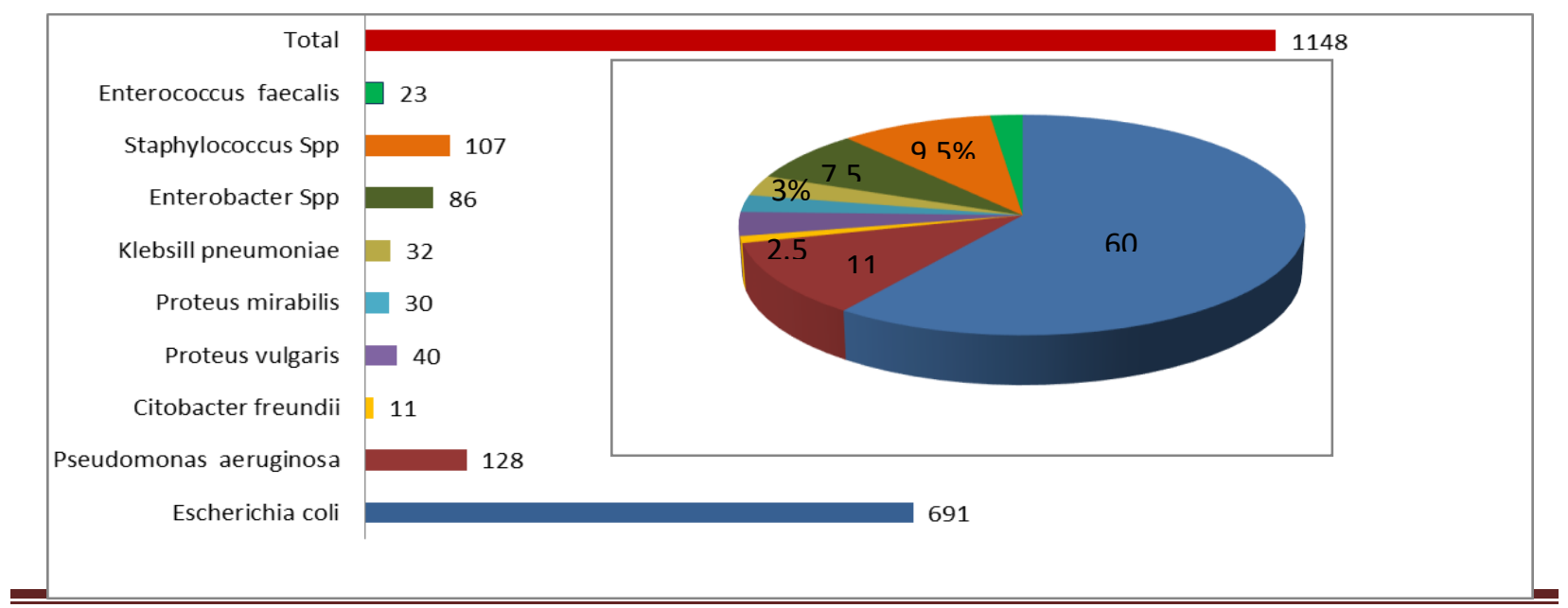


Figure 2: The bar diagram showing the frequency distribution of different organisms among the positive cases $\&$ pie chart showing the percentage of total isolation. Our finding pathogens are Escherichia coli, Enterobacter spp, Pseudomonas aeruginosa, Proteus Vulgaris, Proteus mirabilis, Citrobacter freundii, Klebsiella pneumoniae, Staphylococcus spp, and Enterococcus faecalis. 
International Journal of Medical Science and Health Research

Vol. 5, No. 06; 2021

ISSN: 2581-3366

Table 2. Morphologically and Biochemical test results of the isolated pathogens

\begin{tabular}{|c|c|c|c|c|c|c|c|c|c|c|c|c|c|c|c|c|}
\hline \multirow{3}{*}{$\begin{array}{c}\text { Isolated } \\
\text { pathogens }\end{array}$} & \multicolumn{4}{|c|}{ Microscopic observation } & \multirow{3}{*}{ 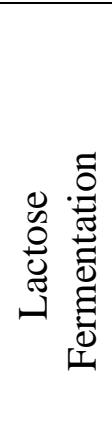 } & \multicolumn{11}{|c|}{ Biochemical test } \\
\hline & \multirow[b]{2}{*}{ 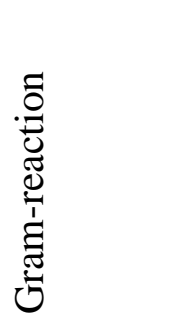 } & \multirow[b]{2}{*}{$\begin{array}{l}\frac{\overline{0}}{0} \\
\overline{0}\end{array}$} & \multirow[b]{2}{*}{ 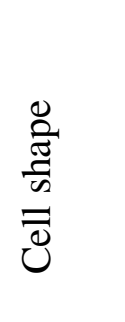 } & \multirow[b]{2}{*}{ 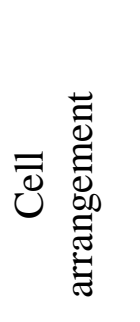 } & & \multicolumn{4}{|c|}{$\begin{array}{c}\mathrm{TS} \\
\mathrm{I}\end{array}$} & \multicolumn{3}{|c|}{$\begin{array}{c}\text { MI } \\
\mathrm{U}\end{array}$} & \multirow[b]{2}{*}{ 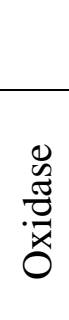 } & \multirow[b]{2}{*}{ 苛 } & \multirow[b]{2}{*}{$\frac{\mathscr{E}}{\tilde{\Xi}}$} & \multirow[b]{2}{*}{ 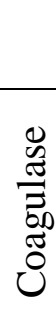 } \\
\hline & & & & & & $\frac{\vec{\Xi}}{\tilde{n}}$ & 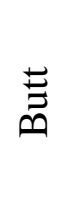 & $\stackrel{\mathscr{I}}{I}$ & $\tilde{\Xi}$ & 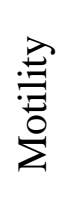 & $\frac{0}{0}$ & 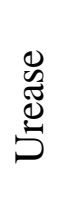 & & & & \\
\hline Escherichia coli & $\begin{array}{c}\text { Gram } \\
\text { negative }\end{array}$ & pink & Rod & Single & + & $\mathrm{Y}$ & $\mathrm{Y}$ & - & $\begin{array}{l}+1 \\
- \\
\end{array}$ & + & + & - & - & - & + & - \\
\hline Enterobacter spp & $\begin{array}{c}\text { Gram } \\
\text { negative }\end{array}$ & Pink & Rod & Single & + & $\mathrm{Y}$ & $\mathrm{Y}$ & - & + & + & - & - & - & + & + & - \\
\hline Proteus vulgaris & $\begin{array}{l}\text { Gram - } \\
\text { negative }\end{array}$ & Pink & Rod & Swarm & - & $\mathrm{Y}$ & $\mathrm{R}$ & + & - & + & + & + & - & - & + & - \\
\hline Proteus mirabilis & $\begin{array}{l}\text { Gram - } \\
\text { negative }\end{array}$ & Pink & Rod & Swarm & - & $\mathrm{Y}$ & $\mathrm{R}$ & + & - & + & - & + & - & - & + & - \\
\hline $\begin{array}{l}\text { Citrobacter } \\
\text { freundii }\end{array}$ & $\begin{array}{l}\text { Gram - } \\
\text { negative }\end{array}$ & pink & Rod & Single & + & $\mathrm{Y}$ & $\mathrm{Y}$ & - & $\begin{array}{c}+1 \\
-\end{array}$ & + & + & - & - & - & + & - \\
\hline $\begin{array}{c}\text { Pseudomonas } \\
\text { aeruginosa }\end{array}$ & $\begin{array}{l}\text { Gram - } \\
\text { negative }\end{array}$ & Pink & Rod & Single & - & $\mathrm{R}$ & $\mathrm{R}$ & - & - & + & - & $\frac{3}{n}$ & + & + & + & - \\
\hline $\begin{array}{c}\text { Klebsiella } \\
\text { pneumoniae }\end{array}$ & $\begin{array}{c}\text { Gram- } \\
\text { negative }\end{array}$ & Pink & Rod & Single & + & $\mathrm{R}$ & $\mathrm{Y}$ & - & + & - & - & $\frac{3}{2}$ & - & + & + & - \\
\hline $\begin{array}{c}\text { Staphylococcus } \\
\text { spp }\end{array}$ & $\begin{array}{l}\text { Gram- } \\
\text { positive }\end{array}$ & Purple & Cocci & Cluster & + & $\mathrm{Y}$ & Y & - & & - & - & + & - & + & + & $\begin{array}{l}\mathrm{N} \\
\text { ot } \\
\text { do } \\
\text { ne }\end{array}$ \\
\hline
\end{tabular}

Table 3. Antibiotic sensitivity pattern on isolated uropathogenes

\begin{tabular}{|c|c|c|c|c|c|c|c|c|c|}
\hline Antibiotic & 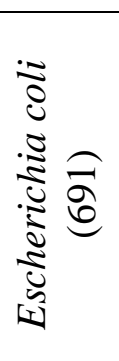 & 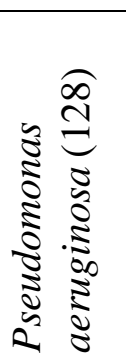 & 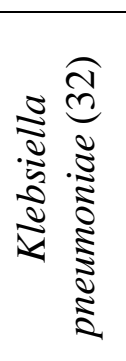 & 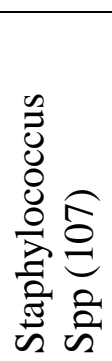 & 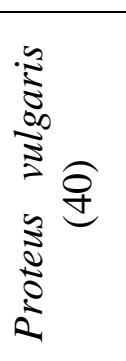 & 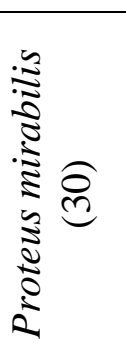 & 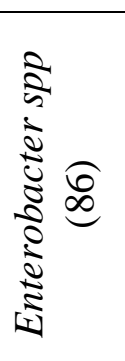 & 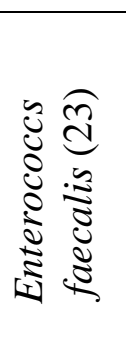 & 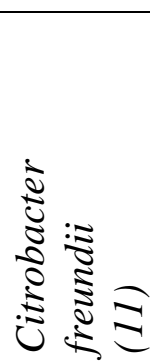 \\
\hline Amoxicillin $(10 \mu \mathrm{g})$ & $02 \%$ & $07 \%$ & $02 \%$ & $20 \%$ & $03 \%$ & $05 \%$ & $05 \%$ & $25 \%$ & $00 \%$ \\
\hline Amoxiclav $(30 \mu \mathrm{g})$ & $71 \%$ & $60 \%$ & $63 \%$ & $70 \%$ & $35 \%$ & $63 \%$ & $38 \%$ & $68 \%$ & $61 \%$ \\
\hline Azithromycin $(15 \mu \mathrm{g})$ & $06 \%$ & $02 \%$ & $00 \%$ & $07 \%$ & $15 \%$ & $16 \%$ & $17 \%$ & $10 \%$ & $00 \%$ \\
\hline Cefixime $(05 \mu \mathrm{g})$ & $15 \%$ & $12 \%$ & $14 \%$ & $05 \%$ & $05 \%$ & $07 \%$ & $05 \%$ & $02 \%$ & $03 \%$ \\
\hline Ceftazidime $(30 \mu \mathrm{g})$ & $18 \%$ & $14 \%$ & $20 \%$ & $08 \%$ & $08 \%$ & $05 \%$ & $11 \%$ & $07 \%$ & $06 \%$ \\
\hline Cefuroxime $(30 \mu \mathrm{g})$ & $14 \%$ & $09 \%$ & $13 \%$ & $07 \%$ & $03 \%$ & $04 \%$ & $08 \%$ & $05 \%$ & $02 \%$ \\
\hline Ciprofloxacin $(05 \mu \mathrm{g})$ & $41 \%$ & $43 \%$ & $32 \%$ & $46 \%$ & $28 \%$ & $31 \%$ & $38 \%$ & $30 \%$ & $33 \%$ \\
\hline Cotrimoxazole $(25 \mu \mathrm{g})$ & $15 \%$ & $21 \%$ & $08 \%$ & $43 \%$ & $25 \%$ & $28 \%$ & $07 \%$ & $02 \%$ & $02 \%$ \\
\hline Ceftriaxone $(30 \mu \mathrm{g})$ & $33 \%$ & $36 \%$ & $28 \%$ & $30 \%$ & $15 \%$ & $18 \%$ & $25 \%$ & $15 \%$ & $30 \%$ \\
\hline Nitrofurantoin $(30 \mu \mathrm{g})$ & $67 \%$ & $31 \%$ & $50 \%$ & $60 \%$ & $56 \%$ & $60 \%$ & $47 \%$ & $59 \%$ & $60 \%$ \\
\hline Amikacin $(30 \mu \mathrm{g})$ & $80 \%$ & $79 \%$ & $71 \%$ & $79 \%$ & $86 \%$ & $84 \%$ & $68 \%$ & $80 \%$ & $83 \%$ \\
\hline Gentamicin $(10 \mu \mathrm{g})$ & $74 \%$ & $72 \%$ & $71 \%$ & $73 \%$ & $82 \%$ & $84 \%$ & $70 \%$ & $73 \%$ & $82 \%$ \\
\hline Meropenem $(10 \mu \mathrm{g})$ & $89 \%$ & $72 \%$ & $82 \%$ & $83 \%$ & $84 \%$ & $84 \%$ & $78 \%$ & $80 \%$ & $88 \%$ \\
\hline Doxycycline $(30 \mu \mathrm{g})$ & $40 \%$ & $38 \%$ & $40 \%$ & $53 \%$ & $30 \%$ & $36 \%$ & $37 \%$ & $20 \%$ & $30 \%$ \\
\hline Levofloxacin $(05 \mu \mathrm{g})$ & $37 \%$ & $47 \%$ & $38 \%$ & $43 \%$ & $40 \%$ & $43 \%$ & $41 \%$ & $20 \%$ & $32 \%$ \\
\hline Linezolid $(30 \mu \mathrm{g})$ & $10 \%$ & $03 \%$ & $02 \%$ & $30 \%$ & $00 \%$ & $00 \%$ & $09 \%$ & $45 \%$ & $00 \%$ \\
\hline Nalidixic Acid $(30 \mu \mathrm{g})$ & $07 \%$ & $15 \%$ & $02 \%$ & $10 \%$ & $15 \%$ & $18 \%$ & $15 \%$ & $00 \%$ & $00 \%$ \\
\hline
\end{tabular}




\section{International Journal of Medical Science and Health Research}

Vol. 5, No. 06; 2021

ISSN: 2581-3366

After performing the cultural \& biochemical test, Gram staining, microscopic observation the existence of total pathogens $1148(100 \%)$ in urine sample were determined as Escherichia coli 691 (60\%), Pseudomonas aeruginosa 128 (11\%), Citobacter freundii 11 (01\%), Proteus vulgaris 40 ( 3.5\%), Proteus mirabilis 30 (2.5\%), Klebsilla pneumoniae 32 (3\%), Enterobacter Spp 86 (7.5\%), Staphylococcus Spp 107 (9.5\%), Enterococcus faecalis 23 (2\%) Figure 2. 17 antibiotics were used against the isolated uropathogens. As it can be seen from (Table 3) Escherichia coli are sensitive to Meropenem 89\%, Amikacin 80\%, Gentamicin 74\%, Nitrofuration 67\%, Amoxiclave 71\%, Ciprofloxacine 41\%, Levofloxacin 37\%, Doxycycline 40\%. Pseudomonas aeruginosa sensitive to to Meropenem 72\%, Amikacin 79\%, Gentamicin 72\%, Nitrofuration 54\%, Amoxiclave 60\%, Ciprofloxacine 43\%, Levofloxacine 47\%. Klebsilla Pneumoniae to Meropenem 82\%, Amikacin 71\%, Gentamicin 71\%, Nitrofuration 50\%, Amoxiclave 63\%, Ciprofloxacine 32\%, Levofloxacine 38\%. Staphylococcus Spp Meropenem 83\%, Amikacin 79\%, Gentamicin 73\%, Nitrofuration 60\%, Amoxiclave 70\%, Ciprofloxacine 46\%, Levofloxacine 43\%, Lenazolid 30\%,Cotrimoxazole 43\%. Proteus vulgaris Meropenem 84\%, Amikacin 86\%, Gentamicin 82\%, Nitrofuration 56\%, Amoxiclave 35\%, Ciprofloxacine 28\%, Levofloxacine 40\%, Doxycycline 30\%. Proteus mirabilis Meropenem 86\%, Amikacin 84\%, Gentamicin 84\%, Nitrofuration 60\%, Amoxiclave 63\%, Ciprofloxacine 31\%, Levofloxacine 43\%, Doxycycline 30\%. Enterobacter Spp Meropenem 78\%, Amikacin 68\%,Gentamicin 70\%, Nitrofuration 47\%, Amoxiclave 58\%, Ciprofloxacine 38\%, Levofloxacine 41\%, Doxycycline 37\%. Enterococcus faecalis Meropenem 80\%, Amikacin 80\%, Gentamicin 73\%, Nitrofuration 59\%, Amoxiclave $68 \%$, Ciprofloxacine $30 \%$, Levofloxacine $20 \%$, Lenazolid 32\%, Cotrimoxazole $43 \%$. Citobacter freundii Meropenem 88\%, Amikacin 83\%, Gentamicin 82\%, Nitrofuration 60\%, Amoxiclave $61 \%$, Ciprofloxacine 33\%, Levofloxacine 32\%, Ceftriaxone 30\%, Doxycycline $30 \%$.

\section{Discussion:}

Urinary tract infection is an emerging issue as a common clinical problem in both the community and healthcare-associated settings. Epidemiological UTI accounts for seven million outdoor visits, one million emergency visits, resulting in 100000 hospitalization visits yearly 31 . Moreover, antimicrobial resistance to uropathogenic creates major health problems worldwide. The study describes the relation between sex, isolated bacterial pathogens, and antibiotic susceptibility patterns. Among the total number of patients 3060, $1148(37.5 \%)$ were culture positive include males \& females. Among 1148 positive samples of UTI of those $248(22 \%)$ male and $900(78 \%)$ female. In our study, $37.5 \%$ positive that is similar with $290(36.1 \%)$ positive out of 804 susceptible participants 22 and $49(31.4 \%)$ positive case out of 156 is not similar with our study 25. Our finding Escherichia coli 691 (60\%), Pseudomonas aeruginosa 128 (11\%), Citrobacter freundii $11(01 \%)$,

Proteus vulgaris 40 (3.5\%), Proteus mirabilis 30 (2.5\%), Klebsiella pneumoniae 32 (3\%), Enterobacter spp 86 (7.5\%), Staphylococcus spp 107 (9.5\%), Enterococcus faecalis 23 (2\%).Two hundred and sixty-seven (267) morning clean catch midstream urine samples were collected from patients attending three hospitals in Bushenyi district. Significant bacteriuria was observed in 86/267 (32.2\%). Escherichia coli was the most prevalent bacterial uropathogen with 36/86 (41.9\%) followed by Staphylococcus aureus 27/86 (31.4\%), Klebsiella pneumoniae 10/86 


\section{International Journal of Medical Science and Health Research}

Vol. 5, No. 06; 2021

ISSN: 2581-3366

(11.6\%), Klebsiella oxytoca (16.3\%), Proteus spp (12\%), Enterococcus faecalis (4.1\%) 23. that is not similar with our study Escherichia coli (55.1\%), Pseudomonas aeruginosa (4.1\%), Citobacter freundii (02\%), Proteus vulgaris

(3.5\%), Proteus mirabilis (2.5\%), Klebsiella pneumoniae (3\%), Enterobacter Spp (7.5\%), Staphylococcus Spp $(9.5 \%)$, Enterococcus faecalis (2\%)25 that few match with our study.

Escherichia coli (52.9\%)24 was found to be the predominant pathogen that is similar with our study And Klebsiella spp (22.9\%), Proteus spp. (4.7\%), Pseudomonas spp. (4.4\%), Enterobacter spp (2.4\%), Citrobacter spp (3\%)24 are not similar with our study E. coli is the most prominent bacterial isolate that similar with $22,23,24,25$. Among the 1148 positive sample of UTI 248 (22\%) was male and $900(78 \%)$ female that are not similar with male $(49.3 \%)$ \& female $(66.67 \%)$ that is few match with our study. All gram-negative uropathogens are most effective to Meropenem, Gentamicin. Amikacin, Nitrofuraton, Ciprofloxacin, Levofloxacin, Doxycycline and Gram-positive uropathogens are effective to Meropenom, Gentamicin, amikacin, doxacyclin, linezolid that is similar with22. Our finding Gam-negative uropathogens antibiotic sensibility pattern similar with 27. In our study, Amoxiclave are effective on all pathogens that we can compare with 28. Increasing drug resistance is a great concern to common bacterial infections including UTI. Still, antimicrobial agents like Amoxicillin, Azithromycin, Nalidixic Acid, Cefixime, Cotrimoxazole are in place to treat many Gram-positive \& Gram-negative bacterial infection including UTIs in many developed and developing country including south Asian countries like Bangladesh, India. These findings are alarming to the choice of antimicrobial agent. In November 2019 one of our studies showed 33\% positive and E.coli 48\% and Amoxicillin was showed $100 \%$ resistant and Meropenem was $84 \%$ sensitive

32, our recent study so far change from that. Antibiotic resistance among uropathogens has become a public health concern in Bangladesh. The pattern of antibiotic resistance of the microorganism causing infection including UIT varies in their antibiotic susceptibility from place to place \& time to time. Antibiotic abuse due to easy availability \& practicing an incomplete course of antibiotics during infection has promoted antibiotic resistance. The highest number of resistance found in commonly used oral drugs and lower resistance developed in less common use drugs.

\section{Conclusion:}

UTI is a serious health problem all over the world including Bangladesh, also affecting millions people every year. The prevalence of antimicrobial resistance become increasing worldwide and is a major factor in the selection of antibiotics for treatment and misuse of antibiotics. To avoid this danger we have must take an antibiotic as prescribed by a doctor and complete the dose according to the correct rules. And there is a need to create awareness among the people about antibiotic resistance. Regular monitoring is required to establish reliable information about the susceptibility pattern of uropathogenic for optimization of urinary tract infection. The emergence and spread of resistance can be reduce through appropriate use of antimicrobial agents. If it is possible to increase the research and reach the result to physician that helps to select the right antibiotic and reduce the misuse of many antibiotic. 


\section{International Journal of Medical Science and Health Research}

Vol. 5, No. 06; 2021

ISSN: $2581-3366$

\section{References}

Calvin MK (1994).Urinary tract infection in females. clin infect Dis; 18:1-12.

Rahman SR, Ahmed MF, Begum A (2004). Occurrence of Urinary Tract Infection in Adolescent and Adult Women of Shanty Town in Dhaka City in Bangladesh. Ethio Jour of Health Sci; 24 (2):145-152.

Morgan M, McKenzie H (1993). Controversies in the laboratory diagnosis of community acquires urinary tract infection. European Journal of Clinic Microbiology and Infectious Diseases, 12:419- 504. 39.

Feitosa DC, da silvaMG , de Lima Parade CM(2009).Accuracy of simple urine tests for diagnosis of urinary tract infections in low-risk pregnant women. Rev. Latno-Am Entermagem, 17(4):507- 513.

JawetzE. Melninick (1995). Clinical correlation: Urinary tract in medical microbiology.20thEd.London UK prentice Ball Intl.Inc;p:635

BadranYA.El-Kashef TA, AbdelazizAS,Ali MM (2015). Impact of genital hygiene and sexual activity on urinary tract infection during pregnancy. Urology Annals 7(4):478-486

Heilberg IP, Schor N, Abordagem diagnóstica e terapêutica na infecção do trato urinário-ITU. Rev Assoc Med Bras.2003; 49:109-16.

Duarte G, Marcolin AC, Gonçalves CV, Quintana SM, Berezowski AT, Nogueira AA, et al., Infecções urinárias na gravidez: análise dos métodos para diagnóstico e do tratamento. Rev Bras Ginecol Obstet. 2002; 24: 471-7.

Bonny AE and Brouhard BH (2005). "Urinary tract Infection in the among adolescents". Adolescent Medicine16 (1):149-161

Danielle Cristina Alves Feitosa, Márcia Guimarães da Silva, Cristina Maria Garcia de Lima Parada, Accuracy Of Simple Urine Tests For Diagnosis Of Urinary Tract Infections In Low-Risk Pregnant Women Rev Latino-am Enfermagem julho-agosto; 2009; 17(4):50713.

Batista CS. Infecção do trato urinário na gestação - conduta. Femina. 2002; 30:553-5.

Mohsin Raheela, Khurram Mutahir Siddiqui, Recurrent urinary tract infections in females J Pak Med Assoc, 2010;60 (1): 55-59.

Grahan JC. Galloway A (2001).The laboratory diagnosis of urinary tract infection. Jourofclin path; 54:911-919

WilsonML, GaidoL (2004), Laboratory diagnosis of urinary tract infection in adult patients. Clin infect Dis; 34:1150-8

Banadio M, MeiniM, Spetaleri P, Gilgi C(2001), Current microbiological and clinical aspects of urinary tract infections. EurJ Urol; 40:439-45

GrudeN,Tveten Y,Kristiansen BE(2001) .Urinary tract infections in Norway; bacterial etiology and susceptibility, a retrospective study of clinical isolates. Clin Microbial Infect; 7:543-7 


\section{International Journal of Medical Science and Health Research}

Vol. 5, No. 06; 2021

ISSN: $2581-3366$

Cheesbrough M (2000), Summary of the clinical and laboratory features of microorganism. In: District laboratory practice in tropical countries part 2 Cambridge university Press UK: p157-266

Rahman MM, HaqJA, Hossain MA, Sultana R, Islam F, Islam AH (2004), Prevalence of extended spectrum beta-lactamase-producing Eschrichiacoliand Klebsiellapneumonia in an urban hospital in Dhaka Bangladesh Int. JAntimicrob agent; 24(4):508-510

ZinnatS, JahedulMI, JesminA, Ishaque AHMC and Arifuzzaman M(2011).A study of antibiotic susceptibility and resistant patterns of Escherichia coli causing urinary tract infection in chittagong, Bangladesh. Asia Jour of BiolSci 2011;4(7):548-555

Yasmeen BHN, Saad I, Saba I, UddinMM, Jahan R (2015), Prevalence of urinary tract infection, its causative agents and antibiotic sensitivity pattern. A study in northern international medical college Hospital Dhaka. Bang Jour 7(1).

Rahman MM, Haq JA, Hossain MA, SultanaR, Islam F, Islam AH(2004), Prevalence of extended spectrum beta-lactamase-producing Escherichia coli and Klebsiella pneumonia in an urban hospital in Dhaka Bangladesh Int. JAntimicrob agent; 24(4):508-510

A Mahmmad, S N Khan, N Ali, M U Rehman, I Ali Prevalence and Antibiotic susceptibility pattern of uropathogenes in outpatients at a tertiary care hospital. New Microbes and New infections. Volume 36 july 2020.

M Odoki, A Almustapha Aliero, J Tibyangye, J Nyabayo Maniga, E Wampande, C Drago Kato, E Agwu and Bazira. Prevalence Of Bacterial Urinary Tract Infection and Associated Factors among Patient Attending Hospital In Bushen yi District, Uganda. Hindawi International Journal of Microbiology Volume 2019, Article ID 4246780, 8 Pages

FFK Chowdhury, S Ahsan, MS Kabir. Antibiotic resistance patterns of pathogenic Gram negative bacteria isolated from UTI patients in Sirajganj district. Stamford Journal of Microbiology.Vol.3 (1)2013:17-20.

Soloman Yilma Mitiku. Bacterial uropatogens \& their antibiotic susceptibility pattern at dessie Regional Health Laboratory. Pyrex Jurnal of microbiology and Biotechnology. V3 (1) pp1- 9 march 2017

Kolawole A S. Kolawole O M, kandaki Olukemi Y T, Babatundes S K, Durowade K A and Kolawole C F.Prevalancr of urinary tract infection (UTI) among patients attending Dalhatu Ars Specialist Hospital, Lafia Nasarawa state, Nigeria.

Rahman MA, Rahman MZ,Das KP,Rahman MM,Sinha SP,Hossain ME. Antibiotic Sensitivity Pattern of Bacteria Associated with Urinary Tract Infection in a Medical College Hospital of Dhaka. J Brahmanbaria Med College 2019 Jan1(1).

Tomas M, Hooton MD, Delia Scholer PhD, Kalpana Gupta MD, MPH et al. AmoxicillinClavulanate vs Ciprofloxacin for the treatment of uncomplicated cystitis in women. JAMA. 2005;293 (8):949-955. doi:10.1001/jama.293.8.949 
Urinary Tract Infection .Centres of disease control and prevention (CDC) 17th April 2015.

Lane, Dr, Taakhar SS, (August 2011).Diagnosis and management of urinary tract infection and pyelonephritis. Emergency medicine clinic of north America.29 (3):539-52

Joseph TD, Urinary Tract infection and Postatitis. In wells BG, Schwinharmmer TL, Hamiltopn CW,editors. Pharmacotherapy Handbook.7th ed New Yourk: McGraw-Hill; 2008;493503

Nafisa Tabassum, Aklima Akter \& Mrityunjoy Acharjee (2020) Prevalence of Urinary Tract Infection among the Patients Admitted in the Brahmanbaria Medical College Hospital in Bangladesh. Merit Res.J. Med.Sci; Vo 18 (5) pp111-119 